\title{
Human Endogenous Retroviruses and Their Putative Role in the Development of Autoimmune Disorders Such as Multiple Sclerosis
}

\author{
Victoria Gröger and Holger Cynis * \\ Department of Drug Design and Target Validation, Fraunhofer Institute for Cell Therapy and Immunology, Halle, Germany
}

Human endogenous retroviruses (HERVs) are remnants of retroviral germ line infections of human ancestors and make up $8 \%$ of the human genome. Under physiological conditions, these elements are frequently inactive or non-functional due to deactivating mutations and epigenetic control. However, they can be reactivated under certain pathological conditions and produce viral transcripts and proteins. Several disorders, like multiple sclerosis or amyotrophic lateral sclerosis are associated with increased HERV expression. Although their detailed contribution to individual diseases has yet to be elucidated, an increasing number of studies in vitro and in vivo suggest HERVs as potent modulators of the immune system. They are able to affect the transcription of

OPEN ACCESS

Edited by:

Gkikas Magiorkinis, National and Kapodistrian University of Athens, Greece

Reviewed by: Tara Patricia Hurst, Abcam, United Kingdom

Masaaki Miyazawa, Kindai University, Japan

*Correspondence: Holger Cynis holger.cynis@izi.fraunhofer.de

Specialty section:

This article was submitted to

Virology,

a section of the journal

Frontiers in Microbiology

Received: 05 October 2017 Accepted: 05 February 2018 Published: 20 February 2018

Citation:

Gröger V and Cynis H (2018) Human Endogenous Retroviruses and Their Putative Role in the Development of Autoimmune Disorders Such as Multiple Sclerosis.

Front. Microbiol. 9:265 doi: 10.3389/fmicb.2018.00265 other immune-related genes, interact with pattern recognition receptors, and influence the positive and negative selection of developing thymocytes. Interestingly, HERV envelope proteins can both stimulate and suppress immune responses based on different mechanisms. In the light of HERV proteins becoming an emerging drug target for autoimmune-related disorders and cancer, we will provide an overview on recent findings of the complex interactions between HERVs and the human immune system with a focus on autoimmunity.

Keywords: HERV, immune system, autoimmunity, superantigen, disease

\section{INTRODUCTION}

Retroelements constitute a large portion (42\%) of our genome (Lander et al., 2001; Cho et al., 2008; Young et al., 2013). These transposable elements, which have RNA intermediates, are often neglected although their contribution to the human entity is not well-understood.

They are discriminated by the presence of long terminal repeats (LTRs) fundamental for regulation of retroviral gene expression (Mita and Boeke, 2016). Short interspersed nuclear elements (SINEs, without reverse transcriptase) and long interspersed nuclear elements (LINEs, with reverse transcriptase) belong to retroelements that do not possess LTRs (Mita and Boeke, 2016). LTR-positive retroelements encompass $8 \%$ of the human genome (Lander et al., 2001; Balada et al., 2009). They are either called retrotransposons or human endogenous retroviruses (HERVs) according to the absence or presence of the envelope (env) gene, respectively. Hence, HERVs represent the most complete form of retroelements. They entered the primate genome by exogenous retrovirus infections (Belshaw et al., 2004; Young et al., 2013). Retroviruses usually infect somatic cells, but on occasion germ line cells are also targeted. As a consequence, retroviral sequences were transmitted vertically to the offspring in a Mendelian manner and became fixed in the human population (Christensen, 2010). 
HERVs are extensively distributed throughout the human genome due to amplification and transposition events. Based on sequence similarities to exogenous retroviruses, HERVs belong to class I (gamma- and epsilon-like), class II (lenti-, alpha-, beta-, and delta-like) or class III (spuma-like) retroviruses (Gifford et al., 2005; Balada et al., 2010). Phylogenetic studies revealed that at least 30 different HERV families exist in the human genome, each resulting from a distinct infection of the germ line (Bénit et al., 2003; Katzourakis et al., 2005; Stoye, 2012). Among them, HERV-K (HML-2) elements integrated most recently and thus are the most intact and biologically active forms (Marchi et al., 2014). Although the number and diversity of HERVs are huge, nomenclature is still not standardized. While most HERVs are named after the tRNA species used to prime reverse transcription (e.g., HERV-W for tryptophan tRNA), some names are still linked to the approaches applied for their identification. For more details refer to Vargiu et al. (2016).

In the course of human evolution most HERVs have accumulated mutations, which rendered a large fraction of their retroviral sequences non-functional (de Parseval and Heidmann, 2005). There are only two full-length proviruses known from the most recently integrated HERV-K family (HERV-K113, HERV-K115), which show complete reading frames for all viral genes (Turner et al., 2001). However, no infectious endogenous retrovirus has yet been identified in humans (Balada et al., 2009; Stoye, 2012). Nevertheless, intact open reading frames of single retroviral genes persisted in the genome, which gave rise to RNA transcripts as well as proteins and therefore suggesting functions in the human body (de Parseval and Heidmann, 2005).

In this regard, a well-investigated example is syncytin-1, which is an ancient Env protein from the HERV-W family. It encodes a $60 \mathrm{kDa}$ large viral glycoprotein with fusogenic properties and possesses an essential function in placental development in humans (Dupressoir et al., 2012; Bolze et al., 2017). Independent integration events of syncytins, which share functional properties but are derived from multiple ERV lineages, are also important for placental development of many other mammals (Dupressoir et al., 2012; Imakawa and Nakagawa, 2017). Furthermore, HERV transcripts are upregulated during early human embryogenesis with possible implications in early viral defense pathways (Grow et al., 2015).

In surveys of the human genome, a limited number of 16 coding env genes were identified (de Parseval et al., 2003; Villesen et al., 2004). Although it cannot be excluded that shorter ORFs may play a role in cellular processes, it is more probable for long ORFs to have retained their original function. Consequently, the human genome bears a number of retroviral proteins with putative roles in pathophysiological conditions (Hansen et al., 2017). As an example, in amyotrophic lateral sclerosis (ALS), recent research suggested a possible involvement of HERVs (Alfahad and Nath, 2013). It was shown that HERV-K expression in human neurons causes retraction and beading of neurites (Li et al., 2015). As the virus was found to be expressed in neurons of ALS patients but not in neurons of healthy controls it was concluded that HERV-K expression might contribute to neurodegeneration (Li et al., 2015). These results are supported by findings showing increased HERV-K expression in brain tissue of ALS patients compared to non-ALS individuals (Douville et al., 2011).

The focus of the present mini-review is the putative interaction of HERV proteins with the human immune system. Different mechanisms have been proposed to explain HERV interaction with the immune response. With focus on adaptive immune mechanisms, superantigen motifs, and viral proteins will be discussed. Concerning innate immunity, interaction of HERVs with pattern recognition receptors (PRRs) like Toll-like receptor 4 (TLR4) and cluster of differentiation (CD) 14 are described. Immunosuppressive function of HERVs will be also addressed.

\section{INTERACTION OF HERV PROTEINS WITH THE HUMAN IMMUNE SYSTEM}

As part of the human genome, HERV-encoded proteins should be considered as self-antigens and tolerated by the immune system. However, they could be perceived as neo-antigens if not expressed in the thymus during acquisition of immune tolerance (Balada et al., 2009). Moreover, once descended from exogenous viruses, HERVs share sequence homologies with their ancestors, which could provide antigenic epitopes for lymphocyte recognition (Voisset et al., 2008). The underlying mechanism is called molecular mimicry. Here, proteins of infectious agents such as viruses or bacteria and self-derived proteins share structural, functional or immunological similarities. In this light, sequence similarities between Env proteins of HERV-W and myelin are supposed to potentially trigger an immune response in multiple sclerosis (MS) (Ramasamy et al., 2017). There are a number of computationally predicted epitopes, which are shared between retroviruses and host proteins, although biological significance is not always given (Fujinami et al., 2006). Nevertheless, molecular mimicry could help to explain how viral infection leads to autoimmunity.

Retroviral nucleic acids and viral proteins can be sensed by a variety of PRRs, such as Toll-like receptors (TLRs) or NOD-like receptors (Thompson et al., 2011). It is conceivable that HERVencoded proteins are able to trigger PRRs of the innate immune system leading to an induction of autoimmunity (Tugnet et al., 2013). A direct interaction between certain HERV proteins and TLRs has been shown. As an example, the surface unit of HERVW Env binds to TLR4 and CD14 and stimulates the production of pro-inflammatory cytokines including IL-1 beta, IL-6, and TNFalpha (Rolland et al., 2006). A more detailed description of innate immune response activation by HERVs has been compiled by Hurst et al. (Hurst and Magiorkinis, 2015).

Retroviral envelope proteins are hypothesized to both trigger and suppress an immune response. In this context, a peptide of 14 amino acids (LQARILAVERYLKD) located in the transmembrane (TM) glycoprotein gp41 of HIV-1 inhibits mitogen-induced and lymphokine-dependent T-lymphocyte proliferation (Denner et al., 1994; Mühle et al., 2017). It is also able to modulate cytokine levels as it increases IL-6 and IL-10 and decreases IL-2 and CXCL9 expression in human peripheral blood mononuclear cells (PBMCs) (Denner et al., 2013). Thereby, 
it allows the virus to persist and replicate in host cells (Blinov et al., 2013; Denner, 2014). This short sequence, called the immunosuppressive domain (ISD), is highly conserved among retroviruses. It was first described for murine and feline Ctype retroviruses and later extended to human T-lymphotropic virus (HTLV) and HIV (Haraguchi et al., 1997). A similar but not identical sequence $\mathrm{N}$-terminally to the immunodominant Cys-Cys loop can be found in some HERV families including HERV-W, HERV-FRD, and HERV-K (Morozov et al., 2013). A recombinant TM protein and a peptide corresponding to the ISD in HERV-K were shown to inhibit proliferation of human immune cells and to modulate cytokine release similar to the ISD of HIV-1 (Morozov et al., 2013), although corroboration of these findings by other groups is pending. Moreover, the envelope protein Env59 of HERV-H shows anti-inflammatory effects in an experimental arthritis model (Laska et al., 2016). In contrast to a study by Tolosa et al. showing reduced immune response of PBMCs to treatment with LPS and syncytin-1 (HERV-W) (Tolosa et al., 2012), Mangeney et al. described immunomodulatory properties for syncytin-2 (HERV-FRD) but not for syncytin-1 (Mangeney et al., 2007). However, the replacement of two amino acids in the ISD of syncytin-1 with those of syncytin-2 was able to restore the immunosuppressive function (Mangeney et al., 2007). Therefore, syncytins may help to protect the fetus from the mother's immune system (Blaise et al., 2003; Mangeney et al., 2007). HERVs might also help tumor growth by shielding it from the host immune system (Kudo-Saito et al., 2014). This was shown for a synthetic peptide corresponding to the ISD of HERV-H as it causes CCL19-mediated CD271 ${ }^{+}$cell-governing immunosuppression in stimulated human tumor cells (KudoSaito et al., 2014). HERV-H could also be an important factor for immune defense in cancer. Although the association of HERVs with cancerous tissues is beyond the scope of this review, it has been hypothesized that immune suppression by HERVs could contribute to tumor immune evasion.

\section{REGULATION OF HERV EXPRESSION}

HERV expression is tightly regulated by the host through epigenetic mechanisms, which results in varying expression from tissue to tissue (Hurst and Magiorkinis, 2017). Control of HERV expression depends upon regulation of the LTRs, which are able to bind nuclear transcription factors and function as promoters (Hurst and Magiorkinis, 2017). Both CpG methylation of DNA and histone deacetylation keep HERVs silenced, although histone modifications alone were shown to be insufficient for efficient transcription suppression (Hurst et al., 2016). Retroviral genes are heavily methylated in normal tissues, whereas tumors show increased levels of HERV transcripts due to hypomethylation (Cegolon et al., 2013). In addition to epigenetic regulation, other factors including hormones, microorganisms, and the environment were shown to modulate HERV expression (Balada et al., 2009; Emmer et al., 2014).

In this regard, the Epstein-Barr virus (EBV) is able to transactivate the expression of the normally inactive HERV-K18 Env protein, e.g., in resting B lymphocytes via CD21 receptor interaction (Sutkowski et al., 2001; Hsiao et al., 2006; Balada et al., 2009). The mechanism of transactivation was further shown to depend on the expression of the major EBV late gene transactivator EBNA-2 (Sutkowski et al., 2004). In-depth analysis identified the EBV latent membrane protein LMP-2A as a strong candidate for the transactivation of HERV-K18 (Sutkowski et al., 2004). Furthermore, Stauffer et al. showed that interferon- $\alpha$ upregulates transcription of the HERV-K18 env gene, suggesting an indirect connection between viral infections and autoimmune disorders (Stauffer et al., 2001). This is of great interest since HERV-K18 has been reported to have superantigen activity (Sutkowski et al., 2001; Tai et al., 2006), although conflicting data are also published (Lapatschek et al., 2000; Azar and Thibodeau, 2002).

Superantigens activate B- and T-lymphocytes regardless of the specificity of their antigen receptor. They are produced by bacteria and viruses and do not need to be processed as conventional antigens for antigen presentation (Solanki et al., 2008). They bind to conserved regions of major histocompatibility complex (MHC) class II molecules outside of the classical peptide-binding groove and connect them with a subset of T-cells expressing particular T cell receptor (TCR) $\beta$ chain variable region genes (Solanki et al., 2008). This is different from conventional T-cell activation where highly variable TCR $\alpha$ and $\beta$ chains CDR3 regions are bound (Sutkowski et al., 2001). Therefore, superantigens can stimulate many subsets of T-cells expressing the same V $\beta$ genes, followed by massive cytokine secretion (Solanki et al., 2008).

In this context, the first HERV superantigen was isolated by Conrad et al. from pancreatic islets of patients with type I diabetes (T1D) (Conrad et al., 1997). They showed that the Env protein of this new HERV initially named IDDMK $_{1,2} 22$ has properties of a V $\beta 7$-specific superantigen. Sequence analysis revealed that $\mathrm{IDDMK}_{1,2} 22$ corresponds to one allele of the polymorphic HERV-K18 env (Stauffer et al., 2001). Sutkowski et al. further showed an activation of TCR V $\beta 13 \mathrm{~T}$ cells in response to murine $\mathrm{B}$ cells transfected with HERV-K18 env gene (Sutkowski et al., 2001). Tai and colleagues found similar results for $\mathrm{K} 18 \mathrm{Env}$ in mice as it expands V $\beta 7$ and $\mathrm{V} \beta 13 \mathrm{~T}$ cells (Tai et al., 2006; Emmer et al., 2014). Although HERV-K18 Env seems to possess superantigenic properties, its contribution to pathogenesis of T1D remains unclear. Contrary to studies supporting the initial association of the putative superantigen with T1D (Kinjo et al., 2001; Marguerat et al., 2004), four independent studies challenged this hypothesis (Badenhoop et al., 1999; Jaeckel et al., 1999; Knerr et al., 1999; Muir et al., 1999). In summary, the expression of HERVs in the human body is subject to strict regulation, which can lead to an increase in HERV transcripts and proteins due to pathological alterations.

\section{IMPLICATIONS FOR AUTOIMMUNE DISORDERS}

The diversity of as many as 80 different types of autoimmune disorders as well as their clinical resemblance often makes diagnosis difficult. It is known that many different genetic loci with small effect sizes predispose individuals to develop autoimmunity, but in addition, environmental factors play a role in triggering the immune response (Ercolini and Miller, 2009). 
Here, HERVs might play an important role in the homeostasis of the immune system and could be key players when it comes to development of autoimmunity.

Studies that show an association between HERVs and autoimmune diseases either rely on retroviral antigens at the site of disease or the presence of antiretroviral antibodies in the sera of patients (Herve et al., 2002; Mameli et al., 2007; Laska et al.,
2012; Alfahad and Nath, 2013). It has been hypothesized that HERVs are involved in the pathogenesis of diseases characterized by dysregulated immune response, such as autoimmune diseases (Table 1). However, whether HERVs are causative or only a consequence of disease is still under debate, as the expression of HERV mRNA or proteins at the site of tissue injury alone is insufficient to prove a pathogenic role of HERVs.

TABLE 1 | Summary of HERVs associated with inflammatory diseases mainly through genetic, serological, and molecular studies.

\begin{tabular}{|c|c|c|c|}
\hline Diagnosis & HERV & Main results & References \\
\hline \multirow[t]{12}{*}{ MS } & HERV-W & $\begin{array}{l}\text { Meta-analysis of HERV-W viral protein and/or mRNA expression in peripheral blood, CSF, and brain } \\
\text { of MS patients reveals an association between HERV-W and MS }\end{array}$ & Morandi et al., 2017 \\
\hline & & $\begin{array}{l}\text { Accumulated HERV-W Gag expression in axonal structures and endothelial cells of active MS } \\
\text { lesions, HERV-W Env expression in macrophages is restricted to early MS lesions }\end{array}$ & Perron et al., 2005 \\
\hline & & $\begin{array}{l}\text { HERV-W Env is upregulated within MS plaques and correlated with the extent of active } \\
\text { demyelination and inflammation, significantly greater accumulation of HERV-W-specific RNAs in MS } \\
\text { brains vs. controls }\end{array}$ & Mameli et al., 2007 \\
\hline & & $\begin{array}{l}\text { HERV-W Env is dominantly expressed in macrophages and microglia in areas of active } \\
\text { demyelination }\end{array}$ & van Horssen et al., 2016 \\
\hline & & MSRV env is significantly increased in PBMC of MS patients & $\begin{array}{l}\text { Perron et al., 2012; } \\
\text { Garcia-Montojo et al., } 2013\end{array}$ \\
\hline & & $\begin{array}{l}\text { HERV-W Env is present in macrophages within MS brain lesions with particular concentrations } \\
\text { around vascular elements, elevated DNA copy numbers in MS patients vs. controls }\end{array}$ & Perron et al., 2012 \\
\hline & HERV-H & $\begin{array}{l}\text { Higher antibody reactivity toward HERV-H Env and significantly higher expression of HERV-H Env } \\
\text { epitopes on B cells and monocytes in patients with active MS }\end{array}$ & Brudek et al., 2009 \\
\hline & HERV-K18 & Increase in MS risk among homozygous carriers of the K18.3 allele in an US American cohort & Tai et al., 2008 \\
\hline & & HERV-K18.3 haplotype is associated with MS susceptibility in a Spanish cohort & de la Hera et al., 2013 \\
\hline & HERV-Fc1 & $\begin{array}{l}\text { Significant increase of HERV-Fc1 RNA in plasma, and HERV-H/F Gag in T cells and monocytes of } \\
\text { patients with active MS compared to controls }\end{array}$ & Laska et al., 2012 \\
\hline & & $\begin{array}{l}\text { Association of the HERV-Fc1 polymorphism rs391745 with bout-onset MS susceptibility in } \\
\text { Southern European cohorts }\end{array}$ & $\begin{array}{l}\text { Hansen et al., 2011; de la } \\
\text { Hera et al., } 2014\end{array}$ \\
\hline & & HERF-Fc1 SNP rs391745 and HERV-K113 SNP rs2435031 synergize in influencing the risk of MS & $\begin{array}{l}\text { Nexø et al., 2015; Nexø } \\
\text { et al., } 2016\end{array}$ \\
\hline
\end{tabular}

\begin{tabular}{|c|c|c|c|}
\hline \multirow[t]{2}{*}{ ALS } & HERV-K & $\begin{array}{l}\text { Increased HERV-K pol transcripts in brain tissue of ALS patients, HERV-K expression correlates } \\
\text { with TDP-43 }\end{array}$ & Douville et al., 2011 \\
\hline & & $\begin{array}{l}\text { HERV-K is expressed in neurons of ALS patients, HERV-K expression is regulated by TDP- } 43 \text { and } \\
\text { causes retraction and beading of neurites in human neurons }\end{array}$ & Li et al., 2015 \\
\hline \multirow[t]{3}{*}{ SLE } & HERV-E & $\begin{array}{l}\text { HERV-E mRNA expression is higher in lupus CD4+ T-cells vs. healthy controls, and positively } \\
\text { correlated with SLE disease activity }\end{array}$ & Wu et al., 2015 \\
\hline & HRES-1 & $\begin{array}{l}\text { Small GTPase encoded by HRES-1 is overexpressed in lupus T-cells and contributes to } \\
\text { mitochondrial dysfunction involved in SLE }\end{array}$ & Caza et al., 2014 \\
\hline & & HRES-1 locus at the 1 q42 chromosomal region influences development and manifestations of SLE & Pullmann et al., 2008 \\
\hline \multirow[t]{5}{*}{ RA } & HERV-K & $\begin{array}{l}\text { Significantly higher serum autoantibodies against a peptide of HERV-K Env in RA patients vs. } \\
\text { healthy controls }\end{array}$ & Mameli et al., 2017 \\
\hline & & Significantly higher HERV-K viral loads in plasma samples from RA patients vs. healthy controls & Reynier et al., 2009 \\
\hline & HERV-K10 & Enhanced expression of HERV-K10 mRNA in RA & Ejtehadi et al., 2006 \\
\hline & & RA patients show significantly elevated levels of HERV-K Gag activity compared to controls & Freimanis et al., 2010 \\
\hline & & $\begin{array}{l}\text { Significantly elevated lgG antibody response to an HERV-K10 Gag peptide in patients with RA vs. } \\
\text { controls }\end{array}$ & Nelson et al., 2014 \\
\hline \multirow[t]{2}{*}{ SS } & HERV-K113 & HERV-K113 is found in $15.6 \%$ of 96 patients with SS & Moyes et al., 2005 \\
\hline & HIAP & Majority of patients with SS have serum antibodies to proteins of HIAP & Sander et al., 2005 \\
\hline JIA & HERV-K18 & HERV-K18 transcript expression significantly elevated in JIA patients vs. controls & Sicat et al., 2005 \\
\hline
\end{tabular}

MS, Multiple sclerosis; ALS, Amyotrophic lateral sclerosis; SLE, Systemic lupus erythematosus; RA, Rheumatoid arthritis; SS, Sjögren's syndrome; JIA, Juvenile idiopathic arthritis. 
As a prominent example, the association of HERVs with MS is extensively discussed (Morandi et al., 2017). The multiple sclerosis associated retrovirus (MSRV) has been observed in leptomeningeal cells shed into cerebrospinal fluid of a patient with progressive MS (Perron et al., 1991). MSRV belongs to a then unknown HERV-W family and encodes a viral envelope protein that is physiologically expressed in microglia cells of normal brain (Perron et al., 2005). It becomes deregulated and is highly expressed in macrophages of active lesions in MS patients (Perron et al., 2005). In rat and human oligodendroglial precursor cells, HERV-W/TLR4 interaction causes both an increase in pro-inflammatory cytokines and nitrosative stress through increased release of inducible nitric oxide synthase. As a result, oligodendroglial differentiation is reduced, which might be the cause of impaired myelin repair observed in MS (Kremer et al., 2013). Antony and colleagues reported similar results for HERV-W Env expression in astrocytes as it leads to neuroinflammation and death of oligodendrocytes (Antony et al., 2004). Interestingly, treatment with specific antibodies against MSRV Env could prevent MS symptoms in a mouse model of experimental autoimmune encephalomyelitis (Perron et al., 2013). Clinical phase $2 \mathrm{~b}$ studies with the same humanized antibody are currently under way in 12 European countries (CHANGE-MS study) with the possibility of an extension (ANGEL-MS study) for patients that have been enrolled in the CHANGE-MS study (Curtin et al., 2015; GeNeuro, 2017). These studies appear promising in terms of the development of potential novel therapies for MS.

HERV-Fc1, which has the potential to express a full-length Env product of 584 aa, and a Gag product of 470 aa might also be involved in the pathogenesis of MS (Nexø et al., 2015). Laska et al. could show an increased expression of HERV-Fcl Gag in PBMCs and four times higher RNA levels in plasma of patients suffering from active MS compared to healthy controls (Laska et al., 2012). HERV-Fc1 is unusual among human proviruses in having only a single known integration in the genome (on the $\mathrm{X}$ chromosome; Nissen et al., 2012). This locus seems to be genetically associated with MS (Hansen et al., 2011; Nexø et al., 2016). Similarly, homozygous carriers of K18.3, which is one of three allelic forms of HERV-K18 Env and displaying superantigenic properties, show an increased risk for MS compared to individuals carrying two K18.2 alleles (Tai et al., 2008).

A possible mechanism of HERV action in MS is inferred from the findings of pre-active plaques in MS patients. These are clusters of activated microglia present in the absence of demyelination and infiltrating leukocytes (van der Valk and Amor, 2009). They can be detected by magnetic resonance

\section{REFERENCES}

Alfahad, T., and Nath, A. (2013). Retroviruses and amyotrophic lateral sclerosis. Antiviral Res. 99, 180-187. doi: 10.1016/j.antiviral.2013.05.006

Antony, J. M., van Marle, G., Opii, W., Butterfield, D. A., Mallet, F., Yong, V. W., et al. (2004). Human endogenous retrovirus glycoprotein-mediated induction of redox reactants causes oligodendrocyte death and demyelination. Nat. Neurosci. 7, 1088-1095. doi: 10.1038/nn1319 imaging (MRI) several months before the appearance of an active lesion (Fazekas et al., 2002). Oligodendrocyte abnormalities and primary damage to myelin appear to be crucially involved (van der Valk and Amor, 2009). Based on these results and HERV expression in active MS lesions (Mameli et al., 2007; Perron et al., 2012; van Horssen et al., 2016), it is tempting to speculate that pathological alterations in MS are supported by HERV protein expression contributing to plaque formation. Further evidence for the role of HERVs in MS would improve our understanding of the etiology and provide new therapeutic insights into MS.

\section{CONCLUSION}

The findings described here suggest that HERV elements may play a role in the pathogenesis of human diseases such as MS or ALS. Particularly in MS, it is conceivable that the formation of HERV Env proteins trigger a damaging cascade that eventually leads to the symptoms of the disease. This assumption could help to integrate unexpected findings, such as pre-active plaques, into the sequence of pathological events (Christensen, 2017). A deeper understanding of HERV expression under physiological and pathophysiological conditions and their interaction with the immune system might help to better explain and combine several factors that contribute to MS. In this regard, the first studies targeting a specific HERV-W Env protein are currently in clinical trials and may provide further evidence of the validity of this novel approach in the near future.

\section{AUTHOR CONTRIBUTIONS}

VG and HC: designed the outline of the manuscript; VG: wrote the manuscript; HC: supervised the writing, edited, and approved the final version of the manuscript.

\section{FUNDING}

The work was supported by an institutional fund from the state government of Sachsen-Anhalt, Germany.

\section{ACKNOWLEDGMENTS}

The authors are grateful to Malte E. Kornhuber, Martin S. Staege, and Alexander Emmer for helpful comments during preparation of the manuscript. The help of Helen Crehan and Susan Barendrecht in reviewing language and grammar is also acknowledged. 
expression from healthy relatives or normal individuals. Diabetes 48, 215-218. doi: $10.2337 /$ diabetes.48.1.215

Balada, E., Ordi-Ros, J., and Vilardell-Tarrés, M. (2009). Molecular mechanisms mediated by human endogenous retroviruses (HERVs) in autoimmunity. Rev. Med. Virol. 19, 273-286. doi: 10.1002/rmv.622

Balada, E., Vilardell-Tarrés, M., and Ordi-Ros, J. (2010). Implication of human endogenous retroviruses in the development of autoimmune diseases. Int. Rev. Immunol. 29, 351-370. doi: 10.3109/08830185.2010.485333

Belshaw, R., Pereira, V., Katzourakis, A., Talbot, G., Paces, J., Burt, A., et al. (2004). Long-term reinfection of the human genome by endogenous retroviruses. Proc. Natl. Acad. Sci. U.S.A. 101, 4894-4899. doi: 10.1073/pnas.0307800101

Bénit, L., Calteau, A., and Heidmann, T. (2003). Characterization of the low-copy HERV-Fc family: evidence for recent integrations in primates of elements with coding envelope genes. Virology 312, 159-168. doi: 10.1016/S0042-6822(03)00163-6

Blaise, S., de Parseval, N., Bénit, L., and Heidmann, T. (2003). Genomewide screening for fusogenic human endogenous retrovirus envelopes identifies syncytin 2, a gene conserved on primate evolution. Proc. Natl. Acad. Sci. U.S.A. 100, 13013-13018. doi: 10.1073/pnas.2132646100

Blinov, V. M., Krasnov, G. S., Shargunov, A. V., Shurdov, M. A., and Zverev, V. V. (2013). Immunosuppressive domains of retroviruses: cell mechanisms of the effect on the human immune system. Mol. Biol. 47, 613-621. doi: 10.1134/S0026893313050026

Bolze, P.-A., Mommert, M., and Mallet, F. (2017). Contribution of syncytins and other endogenous retroviral envelopes to human placenta pathologies. Prog. Mol. Biol. Transl. Sci. 145, 111-162. doi: 10.1016/bs.pmbts.2016.12.005

Brudek, T., Christensen, T., Aagaard, L., Petersen, T., Hansen, H. J., and MøllerLarsen, A. (2009). B cells and monocytes from patients with active multiple sclerosis exhibit increased surface expression of both HERV-H Env and HERV-W Env, accompanied by increased seroreactivity. Retrovirology 6:104. doi: 10.1186/1742-4690-6-104

Caza, T. N., Fernandez, D. R., Talaber, G., Oaks, Z., Haas, M., Madaio, M. P., et al. (2014). HRES-1/Rab4-mediated depletion of Drp1 impairs mitochondrial homeostasis and represents a target for treatment in SLE. Ann. Rheum. Dis. 73, 1888-1897. doi: 10.1136/annrheumdis-2013-203794

Cegolon, L., Salata, C., Weiderpass, E., Vineis, P., Palù, G., and Mastrangelo, G. (2013). Human endogenous retroviruses and cancer prevention: evidence and prospects. BMC Cancer 13:4. doi: 10.1186/1471-2407-13-4

Cho, K., Lee, Y.-K., and Greenhalgh, D. G. (2008). Endogenous retroviruses in systemic response to stress signals. Shock 30, 105-116. doi: 10.1097/SHK.0b013e31816a363f

Christensen, T. (2010). HERVs in neuropathogenesis. J. Neuroimmune Pharmacol. 5, 326-335. doi: 10.1007/s11481-010-9214-y

Christensen, T. (2017). Human endogenous retroviruses in the aetiology of MS. Acta Neurol. Scand. 136 (Suppl. 201), 18-21. doi: 10.1111/ane.12836

Conrad, B., Weissmahr, R. N., Böni, J., Arcari, R., Schüpbach, J., and Mach, B. (1997). A human endogenous retroviral superantigen as candidate autoimmune gene in type I diabetes. Cell 90, 303-313. doi: 10.1016/S0092-8674(00)80338-4

Curtin, F., Perron, H., Faucard, R., Porchet, H., and Lang, A. B. (2015). Treatment against human endogenous retrovirus: a possible personalized medicine approach for multiple sclerosis. Mol. Diagn. Ther. 19, 255-265. doi: 10.1007/s40291-015-0166-Z

de la Hera, B., Varadé, J., García-Montojo, M., Alcina, A., Fedetz, M., Alloza, I., et al. (2014). Human endogenous retrovirus HERV-Fc1 association with multiple sclerosis susceptibility: a meta-analysis. PLoS ONE 9:e90182. doi: 10.1371 /journal.pone.0090182

Denner, J. (2014). The transmembrane proteins contribute to immunodeficiencies induced by HIV-1 and other retroviruses. AIDS 28, 1081-1090. doi: 10.1097/QAD.0000000000000195

Denner, J., Eschricht, M., Lauck, M., Semaan, M., Schlaermann, P., Ryu, H., et al. (2013). Modulation of cytokine release and gene expression by the immunosuppressive domain of gp41 of HIV-1. PLoS ONE 8:e55199. doi: 10.1371/journal.pone.0055199

Denner, J., Norley, S., and Kurth, R. (1994). The immunosuppressive peptide of HIV-1: functional domains and immune response in AIDS patients. AIDS 8, 1063-1072. doi: 10.1097/00002030-199408000-00005 de Parseval, N., and Heidmann, T. (2005). Human endogenous retroviruses: from infectious elements to human genes. Cytogenet. Genome Res. 110, 318-332. doi: 10.1159/000084964

de Parseval, N., Lazar, V., Casella, J.-F., Benit, L., and Heidmann, T. (2003). Survey of human genes of retroviral origin: identification and transcriptome of the genes with coding capacity for complete envelope proteins. J. Virol. 77, 10414-10422. doi: 10.1128/JVI.77.19.10414-10422.2003

Douville, R., Liu, J., Rothstein, J., and Nath, A. (2011). Identification of active loci of a human endogenous retrovirus in neurons of patients with amyotrophic lateral sclerosis. Ann. Neurol. 69, 141-151. doi: 10.1002/ana.22149

Dupressoir, A., Lavialle, C., and Heidmann, T. (2012). From ancestral infectious retroviruses to bona fide cellular genes: role of the captured syncytins in placentation. Placenta 33, 663-671. doi: 10.1016/j.placenta.2012. 05.005

Ejtehadi, H. D., Freimanis, G. L., Ali, H. A., Bowman, S., Alavi, A., Axford, J., et al. (2006). The potential role of human endogenous retrovirus K10 in the pathogenesis of rheumatoid arthritis: a preliminary study. Ann. Rheum. Dis. 65, 612-616. doi: 10.1136/ard.2004.031146

Emmer, A., Staege, M. S., and Kornhuber, M. E. (2014). The retrovirus/superantigen hypothesis of multiple sclerosis. Cell. Mol. Neurobiol. 34, 1087-1096. doi: 10.1007/s10571-014-0100-7

Ercolini, A. M., and Miller, S. D. (2009). The role of infections in autoimmune disease. Clin. Exp. Immunol. 155, 1-15. doi: 10.1111/j.1365-2249.2008.03834.x

Fazekas, F., Ropele, S., Enzinger, C., Seifert, T., and Strasser-Fuchs, S. (2002). Quantitative magnetization transfer imaging of pre-lesional white-matter changes in multiple sclerosis. Mult. Scler. 8, 479-484. doi: 10.1191/1352458502ms860oa

Freimanis, G., Hooley, P., Ejtehadi, H. D., Ali, H. A., Veitch, A., Rylance, P. B., et al. (2010). A role for human endogenous retrovirus-K (HML-2) in rheumatoid arthritis: investigating mechanisms of pathogenesis. Clin. Exp. Immunol. 160, 340-347. doi: 10.1111/j.1365-2249.2010.04110.x

Fujinami, R. S., von Herrath, M. G., Christen, U., and Whitton, J. L. (2006). Molecular mimicry, bystander activation, or viral persistence: infections and autoimmune disease. Clin. Microbiol. Rev. 19, 80-94. doi: 10.1128/CMR.19.1.80-94.2006

Garcia-Montojo, M., Varade, J., Villafuertes, E., de La Hera, B., Hoyas-Fernandez, J., Domínguez-Mozo, M. I., et al. (2013). Expression of human endogenous retrovirus HERV-K18 is associated with clinical severity in osteoarthritis patients. Scand. J. Rheumatol. 42, 498-504. doi: 10.3109/03009742.2013.779021

GeNeuro (2017). GeNeuro Provides Update on GNbAC1 Multiple Sclerosis Clinical Program. Geneva. Available online at: http://www.geneuro.com/data/news/ GeNeuro-PR-Program-Update-ENG.pdf on 01/27/2017

Gifford, R., Kabat, P., Martin, J., Lynch, C., and Tristem, M. (2005). Evolution and distribution of class II-related endogenous retroviruses. J. Virol. 79, 6478-6486. doi: 10.1128/JVI.79.10.6478-6486.2005

Grow, E. J., Flynn, R. A., Chavez, S. L., Bayless, N. L., Wossidlo, M., Wesche, D. J., et al. (2015). Intrinsic retroviral reactivation in human preimplantation embryos and pluripotent cells. Nature 522, 221-225. doi: 10.1038/nature14308

Hansen, B., Oturai, A. B., Harbo, H. F., Celius, E. G., Nissen, K. K., Laska, M. J., et al. (2011). Genetic association of multiple sclerosis with the marker rs 391745 near the endogenous retroviral locus HERV-Fc1: analysis of disease subtypes. PLoS ONE 6:e26438. doi: 10.1371/journal.pone.0026438

Hansen, D. T., Petersen, T., and Christensen, T. (2017). Retroviral envelope proteins: involvement in neuropathogenesis. J. Neurol. Sci. 380, 151-163. doi: 10.1016/j.jns.2017.07.027

Haraguchi, S., Good, R. A., Cianciolo, G. J., Engelman, R. W., and Day, N. K. (1997). Immunosuppressive retroviral peptides: immunopathological implications for immunosuppressive influences of retroviral infections. J. Leukoc. Biol. 61, 654-666.

Herve, C. A., Lugli, E. B., Brand, A., Griffiths, D. J., and Venables, P. J. W. (2002). Autoantibodies to human endogenous retrovirus- $\mathrm{K}$ are frequently detected in health and disease and react with multiple epitopes. Clin. Exp. Immunol. 128, 75-82. doi: 10.1046/j.1365-2249.2002.01735.x

Hsiao, F. C., Lin, M., Tai, A., Chen, G., and Huber, B. T. (2006). Cutting edge: epstein-barr virus transactivates the HERV-K18 superantigen by docking to the human complement receptor 2 (CD21) on primary B cells. J. Immunol. 177, 2056-2060. doi: 10.4049/jimmunol.177.4.2056 
Hurst, T. P., and Magiorkinis, G. (2015). Activation of the innate immune response by endogenous retroviruses. J. Gen. Virol. 96, 1207-1218. doi: 10.1099 /vir.0.000017

Hurst, T. P., and Magiorkinis, G. (2017). Epigenetic control of human endogenous retrovirus expression: focus on Regulation of Long-Terminal Repeats (LTRs). Viruses 9:E130. doi: 10.3390/v9060130

Hurst, T. P., Pace, M., Katzourakis, A., Phillips, R., Klenerman, P., Frater, J., et al. (2016). Human endogenous retrovirus (HERV) expression is not induced by treatment with the histone deacetylase (HDAC) inhibitors in cellular models of HIV-1 latency. Retrovirology 13:10. doi: 10.1186/s12977-016-0242-4

Imakawa, K., and Nakagawa, S. (2017). The phylogeny of placental evolution through dynamic integrations of retrotransposons. Prog. Mol. Biol. Transl. Sci. 145, 89-109. doi: 10.1016/bs.pmbts.2016.12.004

Jaeckel, E., Heringlake, S., Berger, D., Brabant, G., Hunsmann, G., and Manns, M. P. (1999). No evidence for association between $\operatorname{IDDMK}(1,2) 22$, a novel isolated retrovirus, and IDDM. Diabetes 48, 209-214. doi: 10.2337/diabetes.48.1.209

Katzourakis, A., Rambaut, A., and Pybus, O. G. (2005). The evolutionary dynamics of endogenous retroviruses. Trends Microbiol. 13, 463-468. doi: 10.1016/j.tim.2005.08.004

Kinjo, Y., Matsuura, N., Yokota, Y., Ohtsu, S., Nomoto, K., Komiya, I., et al. (2001). Identification of nonsynonymous polymorphisms in the superantigencoding region of IDDMK1,2 22 and a pilot study on the association between IDDMK1,2 22 and type 1 diabetes. J. Hum. Genet. 46, 712-716. doi: $10.1007 / s 100380170005$

Knerr, I., Repp, R., Dötsch, J., Gratzki, N., Hänze, J., Kapellen, T., et al. (1999). Quantitation of gene expression by real-time PCR disproves a "retroviral hypothesis" for childhood-onset diabetes mellitus. Pediatr. Res. 46, 57-60. doi: 10.1203/00006450-199907000-00010

Kremer, D., Schichel, T., Förster, M., Tzekova, N., Bernard, C., van der Valk, P., et al. (2013). Human endogenous retrovirus type $\mathrm{W}$ envelope protein inhibits oligodendroglial precursor cell differentiation. Ann. Neurol. 74, 721-732. doi: 10.1002/ana.23970

Kudo-Saito, C., Yura, M., Yamamoto, R., and Kawakami, Y. (2014). Induction of immunoregulatory $\mathrm{CD} 271+$ cells by metastatic tumor cells that express human endogenous retrovirus H. Cancer Res. 74, 1361-1370. doi: 10.1158/0008-5472.CAN-13-1349.

de la Hera, B., Varadé, J., García-Montojo, M., Lamas, J. R., La Encarnación, A., Arroyo, R., et al. (2013). Role of the human endogenous retrovirus HERV-K18 in autoimmune disease susceptibility: study in the Spanish population and meta-analysis. PLoS ONE 8:e62090. doi: 10.1371/journal.pone. 0062090

Lander, E. S., Linton, L. M., Birren, B., Nusbaum, C., Zody, M. C., Baldwin, J., et al. (2001). Initial sequencing and analysis of the human genome. Nature 409, 860-921. doi: 10.1038/35057062

Lapatschek, M., Dürr, S., Löwer, R., Magin, C., Wagner, H., and Miethke, T. (2000). Functional analysis of the env open reading frame in human endogenous retrovirus IDDMK $(1,2) 22$ encoding superantigen activity. J. Virol. 74, 6386-6393. doi: 10.1128/JVI.74.14.6386-6393.2000

Laska, M. J., Brudek, T., Nissen, K. K., Christensen, T., Møller-Larsen, A., Petersen, T., et al. (2012). Expression of HERV-Fcl, a human endogenous retrovirus, is increased in patients with active multiple sclerosis. J. Virol. 86, 3713-3722. doi: 10.1128/JVI.06723-11

Laska, M. J., Troldborg, A., Hauge, E. M., Bahrami, S., and Stengaard-Pedersen, K. (2016). AB0082 anti-inflammatory activity of a human endogenous retroviral genetic element in experimental arthritis. Ann. Rheum. Dis. 75, 924.2-925. doi: 10.1136/annrheumdis-2016-eular.4267

Li, W., Lee, M.-H., Henderson, L., Tyagi, R., Bachani, M., Steiner, J., et al. (2015). Human endogenous retrovirus-K contributes to motor neuron disease. Sci. Transl. Med. 7:307ra153. doi: 10.1126/scitranslmed.aac8201

Mameli, G., Astone, V., Arru, G., Marconi, S., Lovato, L., Serra, C., et al. (2007). Brains and peripheral blood mononuclear cells of multiple sclerosis (MS) patients hyperexpress MS-associated retrovirus/HERV-W endogenous retrovirus, but not Human herpesvirus 6. J. Gen. Virol. 88, 264-274. doi: 10.1099/vir.0.81890-0

Mameli, G., Erre, G. L., Caggiu, E., Mura, S., Cossu, D., Bo, M., et al. (2017). Identification of a HERV-K env surface peptide highly recognized in Rheumatoid Arthritis (RA) patients: a cross-sectional case-control study. Clin. Exp. Immunol. 189, 127-131. doi: 10.1111/cei.12964
Mangeney, M., Renard, M., Schlecht-Louf, G., Bouallaga, I., Heidmann, O., Letzelter, C., et al. (2007). Placental syncytins: genetic disjunction between the fusogenic and immunosuppressive activity of retroviral envelope proteins. Proc. Natl. Acad. Sci. U.S.A. 104, 20534-20539. doi: 10.1073/pnas.07078 73105

Marchi, E., Kanapin, A., Magiorkinis, G., and Belshaw, R. (2014). Unfixed endogenous retroviral insertions in the human population. J. Virol. 88, 9529-9537. doi: 10.1128/JVI.00919-14

Marguerat, S., Wang, W. Y., Todd, J. A., and Conrad, B. (2004). Association of human endogenous retrovirus $\mathrm{K}-18$ polymorphisms with type 1 diabetes. Diabetes 53, 852-854. doi: 10.2337/diabetes.53.3.852

Mita, P., and Boeke, J. D. (2016). How retrotransposons shape genome regulation. Curr. Opin. Genet. Dev. 37, 90-100. doi: 10.1016/j.gde.2016.01.001

Morandi, E., Tanasescu, R., Tarlinton, R. E., Constantinescu, C. S., Zhang, W., Tench, C., et al. (2017). The association between human endogenous retroviruses and multiple sclerosis: a systematic review and meta-analysis. PLoS ONE 12:e0172415. doi: 10.1371/journal.pone.0172415

Morozov, V. A., Dao Thi, V. L., and Denner, J. (2013). The transmembrane protein of the human endogenous retrovirus-K (HERV-K) modulates cytokine release and gene expression. PLoS ONE 8:e70399. doi: 10.1371/journal.pone.00 70399

Moyes, D. L., Martin, A., Sawcer, S., Temperton, N., Worthington, J., Griffiths, D. J., et al. (2005). The distribution of the endogenous retroviruses HERVK113 and HERV-K115 in health and disease. Genomics 86, 337-341. doi: 10.1016/j.ygeno.2005.06.004

Mühle, M., Lehmann, M., Hoffmann, K., Stern, D., Kroniger, T., Luttmann, W., et al. (2017). Antigenic and immunosuppressive properties of a trimeric recombinant transmembrane envelope protein gp41 of HIV-1. PLOS ONE 12:e0173454. doi: 10.1371/journal.pone.0173454

Muir, A., Ruan, Q. G., Marron, M. P., and She, J. X. (1999). The IDDMK(1,2)22 retrovirus is not detectable in either mRNA or genomic DNA from patients with type 1 diabetes. Diabetes 48, 219-222. doi: 10.2337/diabetes.48.1.219

Nelson, P. N., Roden, D., Nevill, A., Freimanis, G. L., Trela, M., Ejtehadi, H. D., et al. (2014). Rheumatoid arthritis is associated with IgG antibodies to human endogenous retrovirus gag matrix: a potential pathogenic mechanism of disease? J. Rheumatol. 41, 1952-1960. doi: 10.3899/jrheum.130502

Nexø, B. A., Jensen, S. B., Nissen, K. K., Hansen, B., and Laska, M. J. (2016). Two endogenous retroviral loci appear to contribute to Multiple Sclerosis. BMC Neurol. 16:57. doi: 10.1186/s12883-016-0580-9

Nexø, B. A., Villesen, P., Nissen, K. K., Lindegaard, H. M., Rossing, P., Petersen, T., et al. (2015). Are human endogenous retroviruses triggers of autoimmune diseases? Unveiling associations of three diseases and viral loci. Immunol. Res. 64, 55-63. doi: 10.1007/s12026-015-8671-z

Nissen, K. K., Laska, M. J., Hansen, B., Pedersen, F. S., and Nexø, B. A. (2012). No additional copies of HERV-Fc1 in the germ line of multiple sclerosis patients. Virol. J. 9:188. doi: 10.1186/1743-422X-9-188

Perron, H., Dougier-Reynaud, H.-L., Lomparski, C., Popa, I., Firouzi, R., Bertrand, J.-B., et al. (2013). Human endogenous retrovirus protein activates innate immunity and promotes experimental allergic encephalomyelitis in mice. PLoS ONE 8:e80128. doi: 10.1371/journal.pone.0080128

Perron, H., Germi, R., Bernard, C., Garcia-Montojo, M., Deluen, C., Farinelli, L., et al. (2012). Human endogenous retrovirus type $\mathrm{W}$ envelope expression in blood and brain cells provides new insights into multiple sclerosis disease. Mult. Scler. 18, 1721-1736. doi: 10.1177/1352458512441381

Perron, H., Lalande, B., Gratacap, B., Laurent, A., Genoulaz, O., Geny, C., et al. (1991). Isolation of retrovirus from patients with multiple sclerosis. Lancet 337, 862-863. doi: 10.1016/0140-6736(91)92579-Q

Perron, H., Lazarini, F., Ruprecht, K., Péchoux-Longin, C., Seilhean, D., Sazdovitch, V., et al. (2005). Human endogenous retrovirus (HERV)-W ENV and GAG proteins: physiological expression in human brain and pathophysiological modulation in multiple sclerosis lesions. J. Neurovirol. 11, 23-33. doi: 10.1080/13550280590901741

Pullmann, R., Bonilla, E., Phillips, P. E., Middleton, F. A., and Perl, A. (2008). Haplotypes of the HRES-1 endogenous retrovirus are associated with development and disease manifestations of systemic lupus erythematosus. Arthritis Rheum. 58, 532-540. doi: 10.1002/art.23161

Ramasamy, R., Joseph, B., and Whittall, T. (2017). Potential molecular mimicry between the human endogenous retrovirus $\mathrm{W}$ family envelope proteins 
and myelin proteins in multiple sclerosis. Immunol. Lett. 183, 79-85. doi: 10.1016/j.imlet.2017.02.003

Reynier, F., Verjat, T., Turrel, F., Imbert, P. E., Marotte, H., Mougin, B., et al. (2009). Increase in human endogenous retrovirus HERV-K (HML-2) viral load in active rheumatoid arthritis. Scand. J. Immunol. 70, 295-299. doi: 10.1111/j.1365-3083.2009.02271.x

Rolland, A., Jouvin-Marche, E., Viret, C., Faure, M., Perron, H., and Marche, P. N. (2006). The envelope protein of a human endogenous retrovirusW family activates innate immunity through CD14/TLR4 and promotes Th1-like responses. J. Immunol. 176, 7636-7644. doi: 10.4049/jimmunol.176. 12.7636

Sander, D. M., Szabo, S., Gallaher, W. R., Deas, J. E., Thompson, J. J., Cao, Y., et al. (2005). Involvement of human intracisternal A-type retroviral particles in autoimmunity. Microsc. Res. Tech. 68, 222-234. doi: 10.1002/jemt. 20234

Sicat, J., Sutkowski, N., and Huber, B. T. (2005). Expression of human endogenous retrovirus HERV-K18 superantigen is elevated in juvenile rheumatoid arthritis. J. Rheumatol. 32, 1821-1831.

Solanki, L. S., Srivastava, N., and Singh, S. (2008). Superantigens: a brief review with special emphasis on dermatologic diseases. Dermatol. Online J. 14:3.

Stauffer, Y., Marguerat, S., Meylan, F., Ucla, C., Sutkowski, N., Huber, B., et al. (2001). Interferon-alpha-induced endogenous superantigen. A model linking environment and autoimmunity. Immunity 15, 591-601. doi: $10.1016 / S 1074-7613(01) 00212-6$

Stoye, J. P. (2012). Studies of endogenous retroviruses reveal a continuing evolutionary saga. Nat. Rev. Microbiol. 10, 395-406. doi: 10.1038/nrmicro2783

Sutkowski, N., Chen, G., Calderon, G., and Huber, B. T. (2004). Epstein-Barr virus latent membrane protein LMP-2A is sufficient for transactivation of the human endogenous retrovirus HERV-K18 superantigen. J. Virol. 78, 7852-7860. doi: 10.1128/JVI.78.14.7852-7860.2004

Sutkowski, N., Conrad, B., Thorley-Lawson, D. A., and Huber, B. T. (2001). Epstein-Barr virus transactivates the human endogenous retrovirus HERV-K18 that encodes a superantigen. Immunity 15, 579-589. doi: $10.1016 /$ S1074-7613(01)00210-2

Tai, A. K., Lin, M., Chang, F., Chen, G., Hsiao, F., Sutkowski, N., et al. (2006). Murine Vbeta3+ and Vbeta7+ T cell subsets are specific targets for the HERV-K18 Env superantigen. J. Immunol. 177, 3178-3184. doi: 10.4049/jimmunol.177.5.3178

Tai, A. K., O’Reilly, E. J., Alroy, K. A., Simon, K. C., Munger, K. L., Huber, B. T., et al. (2008). Human endogenous retrovirus-K18 Env as a risk factor in multiple sclerosis. Mult. Scler. 14, 1175-1180. doi: 10.1177/1352458508094641

Thompson, M. R., Kaminski, J. J., Kurt-Jones, E. A., and Fitzgerald, K. A. (2011). Pattern recognition receptors and the innate immune response to viral infection. Viruses 3, 920-940. doi: 10.3390/v3060920
Tolosa, J. M., Schjenken, J. E., Clifton, V. L., Vargas, A., Barbeau, B., Lowry, P., et al. (2012). The endogenous retroviral envelope protein syncytin-1 inhibits LPS/PHA-stimulated cytokine responses in human blood and is sorted into placental exosomes. Placenta 33, 933-941. doi: 10.1016/j.placenta.2012.08.004

Tugnet, N., Rylance, P., Roden, D., Trela, M., and Nelson, P. (2013). Human Endogenous Retroviruses (HERVs) and autoimmune rheumatic disease: is there a link? Open Rheumatol. J. 7, 13-21. doi: 10.2174/1874312901307010013

Turner, G., Barbulescu, M., Su, M., Jensen-Seaman, M. I., Kidd, K. K., and Lenz, J. (2001). Insertional polymorphisms of full-length endogenous retroviruses in humans. Curr. Biol. 11, 1531-1535. doi: 10.1016/S0960-9822(01)00455-9

van der Valk, P., and Amor, S. (2009). Preactive lesions in multiple sclerosis. Curr. Opin. Neurol. 22, 207-213. doi: 10.1097/WCO.0b013e32832b4c76

van Horssen, J., van der Pol, S., Nijland, P., Amor, S., and Perron, H. (2016). Human endogenous retrovirus $\mathrm{W}$ in brain lesions: Rationale for targeted therapy in multiple sclerosis. Mult. Scler. Relat. Disord. 8, 11-18. doi: 10.1016/j.msard.2016.04.006

Vargiu, L., Rodriguez-Tomé, P., Sperber, G. O., Cadeddu, M., Grandi, N., Blikstad, V., et al. (2016). Classification and characterization of human endogenous retroviruses; mosaic forms are common. Retrovirology 13:7. doi: 10.1186/s12977-015-0232-y

Villesen, P., Aagaard, L., Wiuf, C., and Pedersen, F. S. (2004). Identification of endogenous retroviral reading frames in the human genome. Retrovirology 1:32. doi: $10.1186 / 1742-4690-1-32$

Voisset, C., Weiss, R. A., and Griffiths, D. J. (2008). Human RNA "rumor" viruses: the search for novel human retroviruses in chronic disease. Microbiol. Mol. Biol. Rev. 72, 157-196. doi: 10.1128/MMBR.00033-07

Wu, Z., Mei, X., Zhao, D., Sun, Y., Song, J., Pan, W., et al. (2015). DNA methylation modulates HERV-E expression in CD4+ T cells from systemic lupus erythematosus patients. J. Dermatol. Sci. 77, 110-116. doi: $10.1016 /$ j.jdermsci.2014.12.004

Young, G. R., Stoye, J. P., and Kassiotis, G. (2013). Are human endogenous retroviruses pathogenic? An approach to testing the hypothesis. Bioessays 35, 794-803. doi: 10.1002/bies.201300049

Conflict of Interest Statement: The authors declare that the research was conducted in the absence of any commercial or financial relationships that could be construed as a potential conflict of interest.

Copyright (c) 2018 Gröger and Cynis. This is an open-access article distributed under the terms of the Creative Commons Attribution License (CC BY). The use, distribution or reproduction in other forums is permitted, provided the original author(s) and the copyright owner are credited and that the original publication in this journal is cited, in accordance with accepted academic practice. No use, distribution or reproduction is permitted which does not comply with these terms. 